\title{
Long-term quality of life after endonasal endoscopic resection of adult craniopharyngiomas
}

\author{
Kunal S. Patel, BA, ${ }^{1}$ Shaan M. Raza, MD, ${ }^{1}$ Edward D. McCoul, MD, MPH, ${ }^{2}$ Aikaterini Patrona, MD, ${ }^{1}$ \\ Jeffrey P. Greenfield, MD, PhD, ${ }^{1}$ Mark M. Souweidane, MD, ${ }^{1}$ Vijay K. Anand, MD, ${ }^{2}$ and \\ Theodore H. Schwartz, MD'-3
}

Departments of ${ }^{1}$ Neurological Surgery, ${ }^{2}$ Otolaryngology, and ${ }^{3}$ Neuroscience, Weill Cornell Medical College, NewYork-Presbyterian Hospital, New York, New York

OBJECT Craniopharyngiomas are benign parasellar tumors for which surgical removal, although potentially curative, often leads to morbidity with resulting decreases in quality of life (QOL). The endonasal endoscopic approach is a minimal-access technique for removing these tumors and may reduce postoperative morbidity. The QOL following this method for resection of craniopharyngiomas has not been documented.

METHODS The authors reviewed a database of consecutive endonasal endoscopic surgeries done at Weill Cornell Medical College. Adult patients with histologically proven craniopharyngiomas were included who had completed either only postoperative (> 9 months) or both pre- and postoperative QOL forms, the Anterior Skull Base Quality of Life (ASBQ) questionnaire, and the 22-Item Sinonasal Outcome Test (SNOT-22). Rates of gross-total resection (GTR), complications, and visual and endocrine function were collected. Retrospective independence (Wen score) was also assigned. A contemporaneous group of patients undergoing endonasal endoscopic pituitary macroadenoma resection was used as a control.

RESULTS This study included 33 procedures performed in 31 patients. The average postoperative ASBQ score was 3.35 and the SNOT-22 score was 19.6. Better QOL was associated with GTR and postoperative radiation. Worse QOL was associated with persistent visual defects, hypopituitarism, tumor recurrence, increase in body mass index, and worsening Wen score. In a subset of 10 patients, both pre- and postoperative (>9 months) QOL scores were obtained. Both ASBQ and SNOT-22 scores showed stability and a trend toward improvement, from $2.93 \pm 0.51$ to $2.96 \pm 0.47$ (ASBQ) and $23.7 \pm 10.8$ to $18.4 \pm 11.6$ (SNOT-22). Compared with 62 patients undergoing endoscopic pituitary macroadenoma resection, patients with craniopharyngiomas had worse postoperative QOL on the ASBQ ( 3.35 vs $3.80 ; p=0.023)$ and SNOT-22 (19.6 vs 13.4; $p=0.12$ ).

CONCLUSIONS This report of validated site-specific QOL following endoscopic surgery for craniopharyngiomas shows an overall maintenance of postoperative compared with preoperative QOL. Better QOL could be seen in patients with GTR and radiation therapy, and worse QOL was found in patients with visual or endocrine deficits. Nevertheless, patients with craniopharyngiomas still had worse QOL than those undergoing similar surgery for pituitary macroadenomas, confirming the worse prognosis of craniopharyngiomas even when removed via a minimally invasive approach. These measures should serve as benchmarks for comparison with open transcranial approaches to similar tumors.

http://thejns.org/doi/abs/10.3171/2014.12.JNS141591

KEY WORDS endonasal; endoscopic; craniopharyngioma; quality of life

$\mathrm{T}$ HE management of craniopharyngiomas is fraught with challenges that not only hinder achievement of optimal oncological outcomes but potentially have adverse effects on the quality of life (QOL). At time of presentation, and certainly after treatment, craniopharyn- giomas can be associated with visual field defects, endocrinopathies, hypothalamic syndromes, increased cardiovascular risk, and neurocognitive sequelae. .,9,33,37,46 Although considered benign tumors, their location can impact critical structures such as the optic nerves and chiasm, hypo-

ABBREVIATIONS ASBQ = Anterior Skull Base Quality of Life; BMI = body mass index; GTR = gross-total resection; QOL = quality of life; SNOT-22 = 22-Item Sinonasal Outcome Test.

SUBMITTED July 7, 2014. ACCEPTED December 17, 2014

INCLUDE WHEN CITING Published online April 17, 2015; DOI: 10.3171/2014.12.JNS141591.

DISCLOSURE Dr. Souweidane is a consultant for Aesculap. Dr. Schwartz is a consultant for Karl Storz, owns stock in Vision Sense, and received clinical or research support for this study from the $\mathrm{NIH}$. 
thalamus, pituitary stalk, and vasculature. The capacity to extend into several anatomical compartments, such as the third ventricle and interpeduncular cistern, as well as adhere to adjacent neurovascular structures makes resection a challenge. ${ }^{2,10,20,22,31,41,45}$ As a result of these anatomical factors, aggressive resection can be associated with short- and long-term neurological sequelae and decreases in QOL. 7, ${ }^{7,23,32}$ Subtotal resection followed by radiotherapy results in a better QOL than total resection in pediatric patients, although this treatment paradigm may be associated with delayed long-term sequelae. ${ }^{16}$ Likewise, transsphenoidal surgery has also been shown retrospectively to result in fewer acute complications. ${ }^{32}$

In light of these issues, there is no consensus on a balanced treatment strategy considering open versus endoscopic approaches, subtotal versus aggressive resection, and the role of radiotherapy. ${ }^{39}$ A recent survey has shown a wide diversity in treatment preferences among practicing neurosurgeons. ${ }^{19}$ Even more so, there is extremely limited data on posttreatment QOL, which would most aptly encompass the postoperative neurological, visual, and endocrine issues patients often endure. For example, a surgical cure that may result in endocrine-related morbidity may lead to improved QOL since the patient's sense of well-being and avoidance of radiation may have a greater impact than the need for hormone replacement. The few studies on QOL that exist are generally retrospective, show a decrease in QOL compared with the normal population, and do not include a cohort having endoscopic surgery. 7,32

There is increasing evidence to support the role of endonasal endoscopic approaches in the management of selected subcohorts of patients with craniopharyngioma. ${ }^{22,27} \mathrm{An}$ endoscopic transsphenoidal approach offers a more direct route to the tumor, avoiding brain retraction, minimizing manipulation of the optic nerves and adjacent small perforating vessels, and resulting in equally high gross-total resection (GTR) rates compared with transcranial series, as well as potentially better visual results., ${ }^{3,5,11,13,21,24,27} \mathrm{Al}$ though there are increasing data about the oncological, neurological, and hormonal outcomes for this treatment option, there are no studies assessing postoperative QOL. In an effort to gain a better understanding of the impact of an endoscopic approach in the treatment of craniopharyngiomas, we used accepted site-specific QOL metrics to measure postoperative QOL in a series of patients with craniopharyngiomas by using their own preoperative data as an internal control in a subset of patients, as well as data from a separate group who underwent endonasal endoscopic pituitary surgery, to control for the approach and highlight disease-specific morbidity. Because there are no validated disease-specific QOL metrics for craniopharyngiomas, we used site-specific measures, namely the Anterior Skull Base Quality of Life (ASBQ) questionnaire and the 22-Item Sinonasal Outcome Test (SNOT-22).

\section{Methods}

Weill Cornell institutional review board approval was obtained for this study. A prospectively acquired database on all patients with craniopharyngiomas who were treated via an endonasal endoscopic transsphenoidal approach at
Weill Cornell Medical College between July 2004 and September 2013 was retrospectively reviewed. All surgeries were performed by the senior authors (T.H.S. and V.K.A.). We identified all patients who underwent endonasal endoscopic surgery for histologically proven craniopharyngioma. Only adult ( $>18$-year-old) patients with at least a 9-month follow-up who had completed the QOL forms were included in this study. In more recently treated patients and in those who underwent surgery on a nonemergency basis, both pre- and postoperative QOL forms were completed. In patients whose preoperative visits occurred before we started administering QOL forms or in patients who arrived through the emergency room, only postoperative data were available. In addition, we identified a series of contemporaneous patients who underwent endonasal endoscopic resection of non-hormone-producing pituitary macroadenomas and filled out the same QOL forms. These patients were used as a control group to determine whether QOL following endonasal surgery for craniopharyngiomas differs substantially from that in patients treated for pituitary tumors.

Patient charts were reviewed for presentation, operative characteristics, complications, adjuvant therapy, and postoperative outcomes. A GTR was determined based on pre- and postoperative imaging. Visual data were based on formal visual field testing by a neuro-ophthalmologist and, when not available, assessments of patient vision in neurosurgical clinic visits. Long-term follow-up data were collected from neurosurgical clinic visits and phone interviews. Statistical analysis was performed using 2 -tailed t-tests, with $\mathrm{p} \leq 0.05$ considered statistically significant.

\section{Surgical Procedure}

The endonasal endoscopic transsphenoidal approach for craniopharyngiomas has been previously described in detail. ${ }^{25,27,40}$ Before each case, $0.25 \mathrm{ml}$ of $10 \%$ fluorescein (AK-FLUOR, Akorn) was injected in $10 \mathrm{ml}$ of CSF to aid in visualization of intraoperative CSF leaks. ${ }^{38,43}$ Patients were placed in pin fixation for neuronavigation aided by preoperative imaging. Nasoseptal flaps were harvested when possible for skull base reconstruction. A wide sphenoidotomy and posterior ethmoidectomy were performed. The middle turbinates were identified and lateralized. Bone was then removed from the superior portion of the sella, the tuberculum sellae, and planum sphenoidale. The dura mater above and below the superior intercavernous sinus was opened, and the sinus was cauterized and cut. The tumor was carefully dissected off any adjacent neurovascular structures, internally decompressed, and removed. Every effort was made to preserve the stalk, superior hypophyseal arteries, and floor of the third ventricle. Closure was performed according to our closure algorithm, which has been described in detail..$^{12,26,30,35}$

\section{Quality of Life Assessment}

The QOL was assessed in 2 ways. First, a retrospective Wen class ${ }^{44}$ was assigned both preoperatively and postoperatively from chart review. This technique, albeit less accurate because it is retrospective and caregiver assigned, was used for comparison with prior similar studies. Sec- 
ond, we prospectively administered 2 previously validated QOL questionnaires: the ASBQ ${ }^{17}$ and the SNOT- $22^{36}$ (Tables 1 and 2).

Wen class is a functional classification system that categorizes patients as follows: I, independent; II, independent with some deficit; III, partially dependent; and IV, totally dependent. ${ }^{44}$ Although the ASBQ was originally intended to assess QOL after craniotomy for anterior skull base lesions, it was recently validated for endonasal endoscopic surgery. ${ }^{4}$ In addition, by using this measure, our results can be compared with ASBQ outcomes after craniotomy published in the literature. Both questionnaires were filled

TABLE 1. The ASBQ questionnaire

\begin{tabular}{|c|c|c|c|c|c|}
\hline \multirow[b]{2}{*}{ Question } & \multicolumn{5}{|c|}{ Response } \\
\hline & Poor & Fair & Good & Very Good & Excellent \\
\hline \multicolumn{6}{|l|}{ How would you define your: } \\
\hline 2. Performance at work? & 1 & 2 & 3 & 4 & 5 \\
\hline 3. Performance at home? & 1 & 2 & 3 & 4 & 5 \\
\hline 6. Motivation to perform various activities? & 1 & 2 & 3 & 4 & 5 \\
\hline 7. Relations with your partner? & 1 & 2 & 3 & 4 & 5 \\
\hline 8. Financial or economic status? & 1 & 2 & 3 & 4 & 5 \\
\hline 9. Appetite? & 1 & 2 & 3 & 4 & 5 \\
\hline 10. Sense of taste? & 1 & 2 & 3 & 4 & 5 \\
\hline 14. Amount of eye secretions and tears? & 1 & 2 & 3 & 4 & 5 \\
\hline 15. Eyesight? & 1 & 2 & 3 & 4 & 5 \\
\hline \multicolumn{6}{|l|}{ How well are you able to: } \\
\hline 16. Climb stairs? & 1 & 2 & 3 & 4 & 5 \\
\hline 17. Lean and stand? & 1 & 2 & 3 & 4 & 5 \\
\hline 18. Walk for 100 meters? & 1 & 2 & 3 & 4 & 5 \\
\hline 19. Walk for 10 meters? & 1 & 2 & 3 & 4 & 5 \\
\hline During the past 4 weeks, how frequently did you: & All of the Time & Most of the Time & Some of the Time & Little of the Time & None of the Time \\
\hline 20. Stay in bed during the day? & 1 & 2 & 3 & 4 & 5 \\
\hline 21. Feel tired? & 1 & 2 & 3 & 4 & 5 \\
\hline 28. Feel relaxed or calm? & 5 & 4 & 3 & 2 & 1 \\
\hline During the past 4 weeks, how much did you(r): & Not at All & A Little Bit & Moderately & Quite a Bit & Very Much \\
\hline 29. Participate in social activities? & 1 & 2 & 3 & 4 & 5 \\
\hline 30. Health interfere with your performance? & 5 & 4 & 3 & 2 & 1 \\
\hline 31. Health affect your activity? & 5 & 4 & 3 & 2 & 1 \\
\hline 32. Accomplish? & 1 & 2 & 3 & 4 & 5 \\
\hline \multirow[t]{2}{*}{ 33. Pain interfere with your ability to perform? } & 5 & 4 & 3 & 2 & 1 \\
\hline & Very Weak & Quite Weak & Neither & Quite Strong & Very Strong \\
\hline \multirow{2}{*}{$\begin{array}{l}\text { 34. During the past } 4 \text { weeks, did you feel physically } \\
\text { weak or strong? }\end{array}$} & 1 & 2 & 3 & 4 & 5 \\
\hline & Very Depressed & A Bit Depressed & Neither & A Bit Happy & Very Happy \\
\hline $\begin{array}{l}\text { 35. During the past } 4 \text { weeks, did you feel depressed } \\
\text { or happy? }\end{array}$ & 1 & 2 & 3 & 4 & 5 \\
\hline
\end{tabular}


TABLE 2. The SNOT-22 scoring system

\begin{tabular}{lcccccc}
\hline \multicolumn{1}{c}{ Item } & No Problem & $\begin{array}{c}\text { Very Mild } \\
\text { Problem }\end{array}$ & $\begin{array}{c}\text { Mild or Slight } \\
\text { Problem }\end{array}$ & $\begin{array}{c}\text { Moderate } \\
\text { Problem }\end{array}$ & $\begin{array}{c}\text { Severe } \\
\text { Problem }\end{array}$ & $\begin{array}{c}\text { Problem as Bad } \\
\text { as It Can Be }\end{array}$ \\
\hline 1. Need to blow nose & 0 & 1 & 2 & 3 & 4 & 5 \\
\hline 2. Sneezing & 0 & 1 & 2 & 3 & 4 & 5 \\
\hline 3. Runny nose & 0 & 1 & 2 & 3 & 4 & 5 \\
\hline 4. Cough & 0 & 1 & 2 & 3 & 4 & 5 \\
\hline 5. Postnasal discharge & 0 & 1 & 2 & 3 & 4 & 5 \\
\hline 6. Thick nasal discharge & 0 & 1 & 2 & 3 & 4 & 5 \\
\hline 7. Ear fullness & 0 & 1 & 2 & 3 & 4 & 5 \\
\hline 8. Dizziness & 0 & 1 & 2 & 3 & 4 & 5 \\
\hline 9. Ear pain/pressure & 0 & 1 & 2 & 3 & 4 & 5 \\
\hline 10. Facial pain/pressure & 0 & 1 & 2 & 3 & 4 & 5 \\
\hline 11. Difficulty falling asleep & 0 & 1 & 2 & 3 & 4 & 5 \\
\hline 12. Waking up at night & 0 & 1 & 2 & 3 & 4 & 5 \\
\hline 13. Lack of a good night's sleep & 0 & 1 & 2 & 3 & 4 & 5 \\
\hline 14. Waking up tired & 0 & 1 & 2 & 3 & 4 & 5 \\
\hline 15. Fatigue during the day & 0 & 1 & 2 & 3 & 4 & 5 \\
\hline 16. Reduced productivity & 0 & 1 & 2 & 3 & 4 & 5 \\
\hline 17. Reduced concentration & 0 & 1 & 2 & 3 & 4 & 5 \\
\hline 18. Frustrated/restless/irritable & 0 & 1 & 2 & 3 & 4 & 5 \\
\hline 19. Sad & 0 & 1 & 2 & 3 & 4 & 5 \\
\hline 20. Embarrassed & 0 & 1 & 2 & 3 & 4 & 5 \\
\hline 21. Sense of taste/smell & 0 & 1 & 2 & 3 & 4 & 5 \\
\hline 22. Blockage/congestion of nose & 0 & 1 & 2 & 3 & 4 & 5 \\
\hline
\end{tabular}

out by the patient, either in the office or through a phone interview.

The ASBQ questionnaire (Table 1) consists of 35 questions with responses recorded on a 5-item Likert scale, ranging from 1 to 5 points per item. The scores are reported as a mean ranging from 1.0 to 5.0, with a higher score indicating a better QOL. The SNOT-22 questionnaire (Table 2) consists of 22 questions and responses recorded on a 6-item Likert scale, ranging from 0 to 5 points per item. Total scores range from 0 to 110 , with a higher score indicating a worse QOL.

The ASBQ questionnaire can also be broken down into 5 subtypes representing different dimensions of QOL. These include physical function (questions 5, 16-20, and 31); vitality (questions 6-7, 21-22, 32, and 34-35); pain (questions 23-24 and 33); influence of emotion (questions 8 and 25-28); and specific symptoms (questions 9-15). Preoperative and postoperative scores for each of these dimensions were compared to identify specific dimensions of increased or decreased change.

\section{Results}

Of a total of 43 endonasal endoscopic surgeries for craniopharyngioma, 33 procedures performed in 31 patients met the inclusion criteria. Five patients were excluded because their operations were too recent for data on longterm follow-up to have accrued. Another 5 patients were excluded because they had childhood-onset craniopharyngiomas. Patient characteristics are described in Table 3.
The mean age at surgery was 49.3 years (SD 17.1, range 20-85 years). Twelve surgeries $(38.7 \%)$ were performed in men. The mean follow-up was 40 months (range 9-101 months).

\section{Patient Presentation}

The most common presenting symptom was vision loss, in $27(87.1 \%)$ of 31 patients. Nine patients $(29 \%)$ had presenting symptoms suggestive of hypothalamic-pituitary dysfunction, including hyperphagia, polydipsia, amenorrhea, and short stature. Nine patients (29\%) presented with recurrent tumors. Prior treatments are summarized in Table 3.

\section{Surgical Outcomes}

Surgical outcomes are described in Table 4. A GTR was completed in 21 of 33 operations (63.6\%). Intentional STR was performed in 2 elderly patients with significant medical comorbidities who underwent planned cyst fenestration and decompression. A GTR was attained in 6 $(66.7 \%)$ of the 9 patients who presented to our hospital with recurrent tumors. The overall 30-day surgical complication rate was $15.2 \%$. In the 33 operations there was 1 postoperative CSF leak (3\%), which was repaired with reoperation. Postoperative sinusitis occurred in $1(3 \%)$ of the 33 procedures, and the individual was treated as an outpatient with antibiotics. A high-risk elderly patient with multiple medical comorbidities including coronary artery disease, hypertension, hypercholesterolemia, and obesity 
TABLE 3. Characteristics in 31 patients with craniopharyngiomas

\begin{tabular}{ll}
\hline \multicolumn{1}{c}{ Characteristic } & \multicolumn{1}{c}{ Value } \\
\hline Mean age in yrs (SD) & $49.3(17.1)$ \\
\hline No. of males (\%) & $12(38.7)$ \\
\hline Mean follow-up in mos (range) & $40(9-101)$ \\
\hline No. w/ presentation (\%) & $27(87.1)$ \\
\hline Vision loss & $9(29.0)$ \\
\hline Hypothalamic-pituitary dysfunction & $7(22.6)$ \\
\hline Headache & $1(3.2)$ \\
\hline Behavioral change & $1(3.2)$ \\
\hline Anosmia & $9(29.0)$ \\
\hline Recurrence & 9 \\
\hline No. w/ prior treatment (\%) & $3(33.3)$ \\
\hline Transcranial resection only & $2(22.2)$ \\
\hline Endoscopic resection only & $1(11.1)$ \\
\hline Transcranial resection + radiation therapy & $1(11.1)$ \\
\hline Endoscopic resection + radiation therapy & $1(11.1)$ \\
\hline$>1$ transcranial resection + radiation therapy & $1(11.1)$ \\
\hline Transcranial resection + radiation therapy + endo- & \\
\hline scopic cyst fenestration &
\end{tabular}

had a postoperative course significant for myocardial infarction, meningitis, and pulmonary embolus; this patient died 38 months postoperatively from cardiac complications. The 30 -day perioperative mortality rate was $0 \%$.

\section{Adjuvant Therapy}

Six patients (19.4\%) went on to have postoperative radiation therapy. All but 1 of these 6 patients underwent scheduled adjuvant fractionated proton beam radiation immediately postoperatively. The other patient received fractionated radiotherapy after recurrent tumor was noted more than 1 year postoperatively. In 3 of the patients with postoperative radiation, STR of their tumor had been attained. The other 3 had GTR but presented with recurrent tumor.

\section{Tumor Recurrence}

There were 7 recurrent tumors in 31 patients, for a recurrence rate of $22.6 \%$. The average time to recurrence was 14.3 months. The average duration of recurrence-free survival was 30.3 months (range 6-101 months). There were 2 recurrences in cases with GTR $(6.5 \%$ of 31$)$ and 5 recurrences in cases with STR (16.1\% of 31). Four of the cases with recurrent tumor had received previous adjuvant radiation, whereas the other 3 did not have any adjuvant therapy before recurrence. Recurrent tumor was managed as follows in the 6 cases in which this information was available: with repeat endoscopic transsphenoidal surgery in 2 patients, cyst fenestration in 2 patients, and radiation without surgery in 2 patients. One reoperation resulted in another recurrence, and 1 cyst fenestration resulted in a recurrence that was subsequently treated with resection via craniotomy.
TABLE 4. Surgical outcomes, adjuvant therapy, and recurrence rates for 33 operations in 31 patients with craniopharyngiomas

\begin{tabular}{cc}
\hline \multicolumn{1}{c}{ Outcome } & Value \\
\hline No. w/ GTR (\%) & $21(67.8)^{*}$ \\
\hline No. of postop complications (\%)† & $1(3.0)$ \\
\hline CSF leak & $1(3.0)$ \\
\hline Meningitis & $1(3.0)$ \\
\hline Sinusitis & $1(3.0)$ \\
\hline Myocardial infarction & $1(3.0)$ \\
\hline Pulmonary embolism & $6(19.4)^{*}$ \\
\hline No. w/ adjuvant radiotherapy (\%) & $7(22.6)^{*}$ \\
\hline No. w/ postop recurrence $(\%)$ &
\end{tabular}

* Calculated for 31 patients.

$\dagger$ More than one complication may occur in the same patient.

\section{Visual Outcomes}

Visual deficits were found preoperatively in 27 (87.1\%) of 31 patients (Fig. 1). Four of these patients had total unilateral vision loss, whereas the majority had decreases in visual acuity. Twenty of these patients $(64.5 \%)$ reported subjective improvement in vision postoperatively, whereas 7 patients $(22.6 \%)$ reported no change in vision. No patient reported a decrease in vision postoperatively. On long-term follow-up (> 1 year), 21 of 30 surviving patients (70\%) had normal vision, 5 patients $(16.7 \%)$ had visual impairment in 1 eye, and 4 patients (13.3\%) were blind in 1 eye. No patients were blind in both eyes.

\section{Endocrine Outcome}

Nine patients (29\%) had presenting symptoms suggestive of hypothalamic-pituitary dysfunction, including hyperphagia, polydipsia, amenorrhea, and short stature (Fig. 1). Six patients (19.4\%) had hypopituitarism preoperatively from a previous surgery. Of the 25 patients who had normal endocrine function preoperatively, $15(60 \%)$ went on to develop at least partial hypopituitarism postoperatively. On long-term follow-up, 21 of the 30 surviving patients (70\%) were receiving hormone replacement therapy. However, 5 patients showed improvement, with restoration of several pituitary axes over time. Fifteen $(50 \%)$ had at least 3 hormone replacement medications and $6(20 \%)$ had 1 or 2 hormone replacement medications.

\section{Quality of Life Outcome}

The level of independence was measured using the Wen classification system. Preoperatively 30 patients (96.8\%) were Wen Class I and 1 patient (3.2\%) was Wen Class II; no patients were Wen Class III or IV. On long-term followup, 28 (90.3\%) were Wen Class I, 2 patients (6.5\%) were Wen Class III, and 1 patient (3.2\%) was Wen Class IV. The average preoperative Wen class was 1.03 compared with a postoperative average of $1.20(\mathrm{p}=0.199)$.

Long-term QOL data using the ASBQ and the SNOT22 were obtained in 25 of 31 adult patients. Two-sample t-tests were used to compare the differences in long-term ASBQ and SNOT-22 scores by groups, based on a variety of intraoperative and postoperative variables (Tables 5 and 6). The average long-term postoperative ASBQ score was 


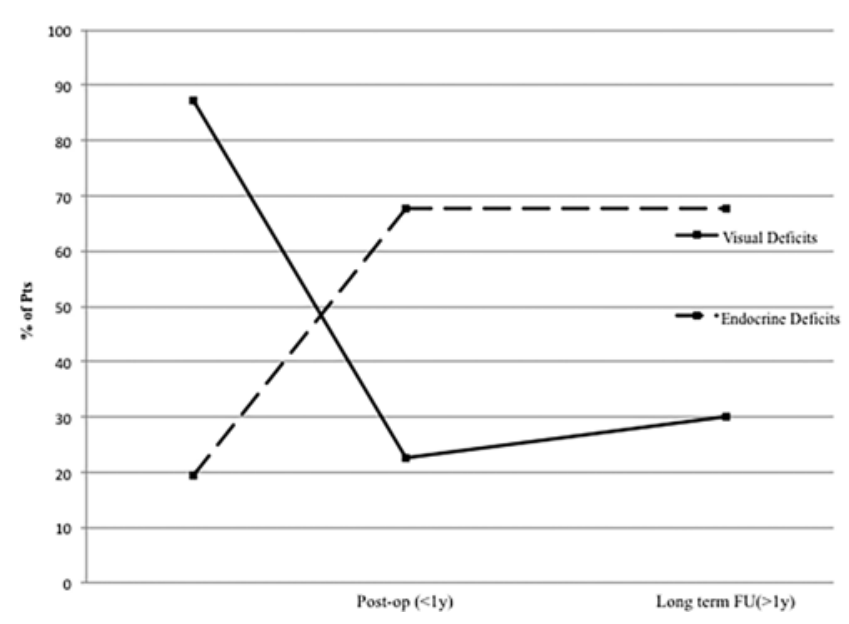

FIG. 1. Graph showing the presence of visual (solid line) and/or endocrine (dashed line) deficits in 31 patients preoperatively, at an early time point postoperatively ( $<1$ year), and at long-term follow-up at least 9 months postoperatively (mean 40 months). Visual deficits largely improved in the immediate postoperative period and stayed stable on long-term follow-up. Endocrine deficits largely appeared in the immediate postoperative period and, similarly to visual deficits, stayed stable on long-term follow-up. FU = follow-up; pts = patients.

3.35 and the SNOT-22 score was 19.6. We compared this to our 2 pediatric patients with QOL data in whom the average long-term postoperative ASBQ score was 3.25 (p $=0.603)$ and SNOT-22 score was $51.5(\mathrm{p}=0.372)$, finding decreased ASBQ and increased SNOT-22 scores, both consistent with decreased QOL. However, the numbers of pediatric patients were too small to reach any significance.

For the ASBQ questionnaire, a higher score indicates a better QOL. An increase in Wen class (a decrease in independence) was the only factor with a statistically significant association with lower ASBQ scores $(p=0.046)$. There were higher scores in the following groups: patients with GTR and those with postoperative radiation. There were lower scores in the following groups: patients with visual defects that persisted $>1$ year after surgery (including patients with new visual defects and those with per-

TABLE 5. The ASBQ scores in 31 patients with craniopharyngiomas*

\begin{tabular}{lcccc}
\hline \multicolumn{1}{c}{ Variable } & + & - & Difference & $\mathrm{p} \mathrm{Value}$ \\
\hline GTR & 3.46 & 3.19 & 0.27 & 0.39 \\
\hline Postop radiation & 3.64 & 3.22 & 0.42 & 0.164 \\
\hline Initial postop visual improvement & 3.53 & 3.52 & 0.01 & 0.974 \\
\hline Long-term visual deficits & 2.99 & 3.52 & -0.53 & 0.150 \\
\hline Hypopituitarism & 3.31 & 3.42 & -0.11 & 0.771 \\
\hline Recurrence & 3.13 & 3.42 & -0.29 & 0.412 \\
\hline Increase in BMI $\geq 2.0$ & 3.15 & 3.51 & -0.36 & 0.300 \\
\hline Postop Wen class $>$ I & 2.33 & 3.49 & -1.16 & 0.075 \\
\hline Postop Wen class increase & 2.33 & 3.49 & -1.16 & 0.046 \\
\hline
\end{tabular}

$+=$ the corresponding variable was present; $-=$ the corresponding variable was not present.

* Higher ASBQ scores are associated with a better QOL. A positive difference value suggests that the corresponding variable is associated with increased QOL.
TABLE 6. The SNOT-22 scores in 31 patients with craniopharyngiomas*

\begin{tabular}{lcrrr}
\hline \multicolumn{1}{c}{ Variable } & + & - & Difference & p Value \\
\hline GTR & 13.1 & 29.5 & -16.4 & 0.035 \\
\hline Postop radiation & 16.3 & 21.2 & -4.9 & 0.501 \\
\hline Initial postop visual improvement & 14.9 & 26.7 & -11.8 & 0.189 \\
\hline Long-term visual deficits & 27.9 & 15.8 & 12.1 & 0.270 \\
\hline Hypopituitarism & 20.6 & 18.0 & 2.6 & 0.755 \\
\hline Recurrence & 24.0 & 18.3 & 5.7 & 0.629 \\
\hline Increase in BMI $\geq 2.0$ & 21.2 & 18.4 & 2.8 & 0.720 \\
\hline Postop Wen class >I & 32.3 & 17.9 & 14.4 & 0.446 \\
\hline Postop Wen class increase & 32.3 & 17.9 & 14.4 & 0.386 \\
\hline
\end{tabular}

* Higher SNOT-22 scores are associated with a lower QOL. A positive difference value suggests that the corresponding variable is associated with decreased QOL.

sistence of preoperative visual deficits), patients who had hypopituitarism (including patients with new hypopituitarism and those who had the condition preoperatively), patients with tumor recurrence postoperatively, patients with an increase in body mass index $(\mathrm{BMI}) \geq 2.0$, patients who were not totally independent as described by Wen class $>$ I, and patients with an increase in Wen class postoperatively.

For the SNOT-22 questionnaire, a higher score indicates a lower QOL. Only patients with GTR had significantly lower scores $(p=0.035)$. There were higher scores in the following groups: patients with postoperative radiation, patients with visual defects that persisted $>1$ year after surgery, patients with hypopituitarism, patients with tumor recurrence postoperatively, patients with an increase in BMI by $\geq 2.0$, patients who were Wen class $>$ I, and patients with an increase in Wen class postoperatively. There were lower scores in the following groups: patients with GTR and patients with initial postoperative visual improvement.

\section{Preoperative Versus Postoperative QOL}

In a subset of 10 patients, we obtained preoperative as well as long-term postoperative QOL scores for comparison. The preoperative mean ASBQ score was $2.93 \pm 0.51$ and the postoperative mean score was $2.96 \pm 0.47$ (Fig. 2). This showed an improvement in QOL after surgery, but was not statistically significant $(\mathrm{p}=0.93)$. The preoperative mean SNOT-22 score was $23.7 \pm 10.8$ and the postoperative mean score was $18.4 \pm 11.6$. This again showed an improvement in QOL because a higher SNOT-22 score indicates worse QOL, but again this was not statistically significant $(\mathrm{p}=0.52)$.

The ASBQ scores can be broken down by different dimensions that make up QOL, including the following: physical function, vitality, pain, emotional changes, and specific symptoms. We compared pre- and postoperative ASBQ scores by dimension and found no significant change.

\section{Comparison With Pituitary Macroadenoma Resection}

We compared the average QOL scores in our series of patients with craniopharyngiomas with a series of 62 

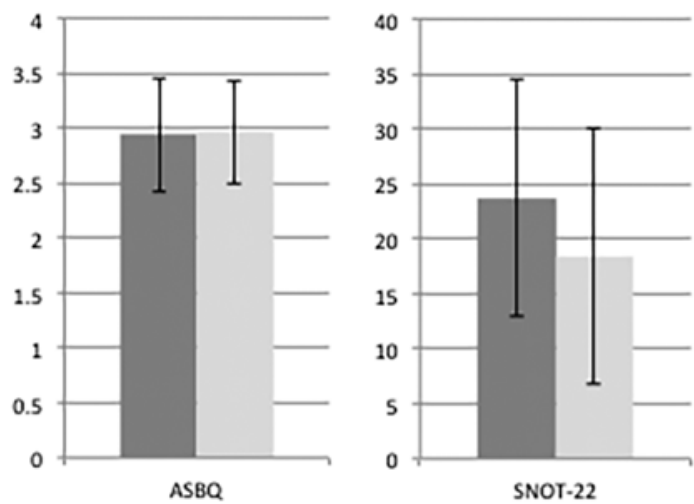

$=$ Pre-Op

E Post-Op

FIG. 2. Bar graphs showing pre- and postoperative ASBQ and SNOT-22 QOL scores for 10 patients. An increase in ASBQ score and decrease in SNOT-22 score both signify an increase in QOL. Bars represent the $95 \%$ confidence interval.

patients with endonasal endoscopic resection of nonhormone-secreting pituitary macroadenomas and long-term (mean 12 months) QOL data by using the ASBQ and SNOT-22 surveys with 2-sample t-tests (Table 7). The cohort with pituitary macroadenomas had an average ASBQ score of 3.80 compared with an average of 3.35 for the cohort with craniopharyngiomas. This yielded a statistically significant difference of $0.45(\mathrm{p}=0.023)$. The cohort with pituitary macroadenomas had an average SNOT-22 score of 13.4, compared with an average of 19.6 for the cohort with craniopharyngiomas, yielding a nonstatistically significant difference of $6.2(\mathrm{p}=0.121)$. These results suggest a potential decrease in QOL in patients with endoscopic resection of craniopharyngiomas compared with those with pituitary macroadenomas (lower ASBQ and higher SNOT-22 scores).

\section{Discussion}

Although they are benign tumors, craniopharyngiomas are known to cause significant morbidity from vision loss, hypothalamic dysfunction, cardiac abnormalities, and endocrinopathies. ${ }^{9}$ Treatment in the form of surgery, radiation, or both, has been implicated in further deterioration. ${ }^{9,24,32}$ In assessing a patient's response to therapy, these traditional surgical end points, however, only tell a portion of the story. In addition to survival, progression-free survival, and morbidity, a patient's QOL is becoming increasingly important in assessment of therapeutic interventions. The QOL is a multidimensional construct that describes an individual's overall perception of well-being. In contrast to the traditional medical history, which is elicited by directed questioning and is liable to subjective estimation by the clinician, QOL is a patient-reported measure that aims to eliminate observer bias. Description of QOL based on a patient-reported instrument is an important aspect of the assessment, because the surgeon's perception of his or her patient's QOL has been shown to be inaccurate in the postoperative period. ${ }^{16}$ The use of QOL assessments may be generalized, disease-specific, or site-specific, and has several potential advantages. These include improved preoperative counseling by the surgeon, better anticipation of the effects of surgery and subsequent recovery by the
TABLE 7. Postoperative (> 12-month) QOL in 25 patients in the craniopharyngioma and 62 in the pituitary macroadenoma cohort

\begin{tabular}{ccccc}
\hline $\begin{array}{c}\text { QOL } \\
\text { Measure }\end{array}$ & Craniopharyngioma & $\begin{array}{c}\text { Pituitary } \\
\text { Macroadenoma }\end{array}$ & $\begin{array}{c}p \\
\text { Difference }\end{array}$ & \begin{tabular}{c} 
Value \\
\hline ASBQ
\end{tabular} \\
\hline SNOT-22 & 3.35 & 3.80 & -0.45 & 0.023 \\
\hline
\end{tabular}

patient, and improved acceptance of the surgical procedure. ${ }^{18}$ In addition, QOL measures may eventually become reportable indicators of the success of surgical intervention and can be used to compare various interventions for efficacy.

The first study of QOL based on a site-specific questionnaire (ASBQ) administered in patients undergoing anterior skull base surgery was reported by Gil et al. ${ }^{15}$ Based on the results of that retrospective, cross-sectional study of 40 patients undergoing open surgical approaches, the authors found that QOL was generally good, and that malignancy, radiotherapy, and comorbidity were negative predictors of QOL. However, lack of preoperative data did not permit conclusions about the change of QOL over time. The ASBQ was subsequently demonstrated to have psychometric validity for site-specific QOL assessment following anterior skull base surgery for both transcranial and endoscopic approaches. ${ }^{4,17}$ A prospective study of QOL in patients undergoing open anterior skull base surgery has only recently been described. Abergel et al. assessed a series of 39 patients with the ASBQ prior to surgery and again at 2 postoperative points. ${ }^{1}$ They found that the QOL scores of most patients undergoing open anterior skull base surgery deteriorate within 6 months after surgery and undergo significant improvement at 12 months postoperatively, but do not rise above their preoperative baseline. McCoul et al. recently showed that, in contrast to open surgery, endonasal endoscopic skull base surgery results in site-specific increases in QOL at 12 weeks and 6 months postoperatively compared with preoperative assessments; however, the majority of these cases were pituitary adenomas. ${ }^{29}$ This study raised the possibility that minimally invasive endonasal endoscopic surgery may be better tolerated than open surgery with respect to QOL.

In this study we report the first prospectively acquired QOL data for craniopharyngioma surgery, including both pre- and postoperative comparisons, in a series of patients undergoing endoscopic endonasal resection. By comparing our data with those in patients who had pituitary lesions and who were undergoing a similar procedure, we clearly show that endonasal surgery can potentially maintain or perhaps slightly improve QOL, even when the goal of surgery is GTR. However, the outcomes are not as favorable as they are following pituitary surgery. This is not surprising because endocrinopathy, visual dysfunction, and increased BMI occur at much higher rates for craniopharyngiomas compared with pituitary tumors, and the rates of GTR are lower and the need for postoperative radiation higher. Consistent with this interpretation is the fact that predictors of worse QOL were young age at diagnosis, persistent visual defects, hypopituitarism, tumor 
recurrence, postoperative radiation, lack of GTR, and increases in BMI.

However, the fact that QOL is maintained and even slightly increased is perhaps unexpected for such a highmorbidity disease. Endonasal endoscopic transsphenoidal resection of craniopharyngiomas, compared with open transcranial approaches, has been shown to result in comparable or even greater rates of extent of resection and GTR. ${ }^{3,5,11,13,21,24,27}$ Moreover, rates of visual improvement may in fact be higher. ${ }^{24}$ Nevertheless, debate regarding the relative merits of endonasal endoscopic surgery compared with open transcranial approaches continues. ${ }^{8}$ Unfortunately, there are no other comparable studies of transcranial craniopharyngioma surgery in existence for comparison at this time because no other study has prospectively examined QOL both pre- and postoperatively to determine the effect of therapy on QOL. Hopefully, such studies using the same ASBQ metric will be forthcoming.

Prior studies have routinely demonstrated a decrease in QOL for patients with craniopharyngioma, either before or after treatment. Several studies have shown dramatic reductions in memory, executive functions, and QOL in pediatric patients with craniopharyngiomas, particularly those with hypothalamic involvement, with as many as $57 \%$ showing neurobehavioral dysfunction. ${ }^{46}$ Three prior studies have examined QOL in adult patients. The more recent study included 29 cured adults with 19 years of follow-up and compared results of 4 health-related questionnaires with those administered to 142 matched controls.? Patients with craniopharyngiomas were found to have significantly worse QOL. Unfortunately, preoperative tests were not administered for comparison, so the impact of treatment on the QOL in these patients was unknown. Predictors of worse QOL were visual field deficit, need for reoperation, postoperative radiation therapy, and female sex. In an earlier study, a similar decrease in QOL was also found compared with controls. ${ }^{23}$ The only study that examined the effect of surgery on QOL was by Mortini et al.; however, only the Wen score was used and it was assigned retrospectively by the authors. ${ }^{32}$ In that study, as in our study, Wen scores were shown to deteriorate. However, the accuracy of a retrospectively assigned Wen score by the treating physician may not be reliable. Indeed, our study demonstrated that although Wen scores retrospectively assigned by the provider worsened, patient-reported prospectively acquired QOL ratings did not.

As opposed to the ASBQ, the assessment of sinonasalrelated QOL in patients undergoing endoscopic surgery has been the subject of several studies. Pant et al. reported on a series of 51 patients undergoing endoscopic surgery who completed the SNOT-22 and ASBQ at 4 postoperative time points. ${ }^{34}$ The investigators found that SNOT-22 scores were significantly better at 6 months and 12 months postoperatively as compared with 1-3 months postoperatively. Conclusions from this study are limited by the absence of preoperative data, unspecified distribution of tumor pathology, and a lack of information about the response rate at each time point. Suberman et al. recently published retrospective data on sinonasal QOL in 50 patients who underwent endoscopic minimally invasive pituitary surgery. ${ }^{42}$ These authors found no difference in Rhinosinusitis
Disability Index scores from preoperative to postoperative time points, and scores were similarly unaffected by the presence or absence of a functional pituitary adenoma. Postoperative assessments were recorded at a single time point for each patient, ranging from 1 month to more than 3 years postoperatively, which may have limited the reliability of the results. Finally, McCoul and colleagues compared preoperative with postoperative SNOT-22 scores in a series of 66 patients and found a transient worsening at 3 weeks that returned to baseline values afterward. ${ }^{28,29}$ Our data are consistent with these previous reports; no significant change in SNOT-22 scores was found $>9$ months after surgery. These data indicate that long-term nasal function is as unchanged for extended craniopharyngioma surgery as it is for pituitary macroadenoma surgery. However, the SNOT-22 score is worse for craniopharyngiomas compared with pituitary tumors, based on the patient's sense of well-being associated with the morbidity of craniopharyngiomas compared with pituitary macroadenomas.

\section{Predictors of Increased or Decreased Postoperative QOL}

We found that GTR was associated with an increased QOL, which was statistically significant $(\mathrm{p}=0.012)$ for results obtained using the SNOT-22 but not ASBQ questionnaires. This is most likely to stem from decreased need for reoperation or radiation therapy, because both were associated with decreased QOL. Although pursing GTR may result in higher rates of endocrinopathy, the deterioration in QOL was more modest when comparing groups with and without postoperative endocrine dysfunction than when comparing groups with and without GTR, suggesting that the benefit of GTR well surpasses the QOL decrease caused by a new endocrinopathy. ${ }^{6}$ The QOL was maintained in our series despite an increase in hypopituitarism from $20 \%$ preoperatively to $70 \%$ postoperatively, and hypopituitarism in the immediate postoperative period did not always translate into a long-term endocrinopathy. Indeed, 5 patients who initially had hypopituitarism eventually regained some pituitary function and were taken off complete hormone supplementation. ${ }^{5,10,11,13,21,32,45}$ Hence, our preliminary data show that hormone replacement is well tolerated and GTR should generally be pursued for cure at the risk of hypopituitarism.

Our series had a recurrence rate of $22.6 \%$, comparable to recurrence rates in recent series with transsphenoidal and transcranial approaches..$^{32}$ Recurrence was associated with a decreased QOL. Of individuals with recurrence, QOL was higher when treated with radiation than with reoperation. This trend has also been seen in other studies but is limited in our analysis due to small sample size and a variety of characteristics that reflect treatment decisions. ${ }^{14}$

Residual symptoms are also expected to have an impact in QOL. Both long-term visual deficits and endocrine deficits were associated with decreased QOL. Obesity is a significant consequence of craniopharyngioma surgery, because disruption of the hypothalamus can lead to hyperphagia. De Vile et al. identified obesity as a risk factor for long-term morbidity of craniopharyngiomas. ${ }^{6}$ Along these lines, we found that an increase in $\mathrm{BMI} \geq 2.0$ was also associated with decreased QOL, suggesting the potential 
importance of developing novel therapies to treat postoperative obesity to preserve QOL.

The strongest correlation with decreased QOL was Wen class, a marker of independence. ${ }^{44}$ Individuals who were not independent on long-term follow-up had lower QOL scores than those who were independent. Similarly, individuals who had an increase in Wen class (a loss of independence) had a statistically significantly lower QOL than those who had no change. Again, this points to the potential importance of physical therapy and emotional support in the postoperative period.

\section{Limitations of the Study}

There are certain limitations of this study. The small sample size of patients with long-term QOL data may lead to a failure to recognize true differences in QOL between different groups. Complications most likely play a large role in QOL outcomes, but due to small numbers of complications, we could not stratify QOL by using this variable. The surveys used to estimate QOL have limitations themselves; they may not capture disease-specific QOL changes caused by craniopharyngiomas, and may instead reflect comorbidities.

\section{Conclusions}

In this first preliminary report of changes in QOL related to surgical intervention for craniopharyngiomas, and specifically endonasal endoscopic surgery, we found preservation of site-specific QOL at an average of 3 years (>9 months) of follow-up. Although lack of GTR and need for reoperation or radiation correlate with worsening QOL, so do worsening vision, increase in BMI, loss of independence, and endocrinopathy. Hence GTR should be pursued, but not at the risk of overwhelming morbidity. Whether endonasal endoscopic surgery preserves QOL better than transcranial surgery cannot be determined at this time due to the lack of pre- to postoperative QOL comparisons in the literature on open transcranial surgery. However, QOL does not improve as dramatically following endonasal craniopharyngioma surgery as it does following endonasal pituitary macroadenoma surgery, probably due to the increased morbidity inherent in the pathophysiology of craniopharyngiomas.

\section{References}

1. Abergel A, Fliss DM, Margalit N, Gil Z: A prospective evaluation of short-term health-related quality of life in patients undergoing anterior skull base surgery. Skull Base 20:27-33, 2010

2. Baskin DS, Wilson CB: Surgical management of craniopharyngiomas. A review of 74 cases. J Neurosurg 65:22-27, 1986

3. Cavallo LM, Prevedello DM, Solari D, Gardner PA, Esposito F, Snyderman CH, et al: Extended endoscopic endonasal transsphenoidal approach for residual or recurrent craniopharyngiomas. J Neurosurg 111:578-589, 2009

4. Cavel O, Abergel A, Margalit N, Fliss DM, Gil Z: Quality of life following endoscopic resection of skull base tumors. J

Neurol Surg B Skull Base 73:112-116, 2012

5. de Divitiis E, Cappabianca P, Cavallo LM, Esposito F, de
Divitiis O, Messina A: Extended endoscopic transsphenoidal approach for extrasellar craniopharyngiomas. Neurosurgery 61 (5 Suppl 2):219-228, 2007

6. de Vile CJ, Grant DB, Hay ward RD, Kendall BE, Neville BG, Stanhope R: Obesity in childhood craniopharyngioma: relation to post-operative hypothalamic damage shown by magnetic resonance imaging. J Clin Endocrinol Metab 81:2734-2737, 1996

7. Dekkers OM, Biermasz NR, Smit JW, Groot LE, Roelfsema F, Romijn JA, et al: Quality of life in treated adult craniopharyngioma patients. Eur J Endocrinol 154:483-489, 2006

8. Elliott RE, Jane JA Jr, Wisoff JH: Surgical management of craniopharyngiomas in children: meta-analysis and comparison of transcranial and transsphenoidal approaches. Neurosurgery 69:630-643, 2011

9. Erfurth EM, Holmer H, Fjalldal SB: Mortality and morbidity in adult craniopharyngioma. Pituitary 16:46-55, 2013

10. Fahlbusch R, Honegger J, Paulus W, Huk W, Buchfelder M: Surgical treatment of craniopharyngiomas: experience with 168 patients. J Neurosurg 90:237-250, 1999

11. Frank G, Pasquini E, Doglietto F, Mazzatenta D, Sciarretta $\mathrm{V}$, Farneti G, et al: The endoscopic extended transsphenoidal approach for craniopharyngiomas. Neurosurgery 59 (1 Suppl 1):ONS75-ONS83, 2006

12. Garcia-Navarro V, Anand VK, Schwartz TH: Gasket seal closure for extended endonasal endoscopic skull base surgery: efficacy in a large case series. World Neurosurg 80:563-568, 2013

13. Gardner PA, Kassam AB, Snyderman CH, Carrau RL, Mintz AH, Grahovac S, et al: Outcomes following endoscopic, expanded endonasal resection of suprasellar craniopharyngiomas: a case series. J Neurosurg 109:6-16, 2008

14. Gautier A, Godbout A, Grosheny C, Tejedor I, Coudert M, Courtillot C, et al: Markers of recurrence and long-term morbidity in craniopharyngioma: a systematic analysis of 171 patients. J Clin Endocrinol Metab 97:1258-1267, 2012

15. Gil Z, Abergel A, Spektor S, Cohen JT, Khafif A, Shabtai E, et al: Quality of life following surgery for anterior skull base tumors. Arch Otolaryngol Head Neck Surg 129:13031309,2003

16. Gil Z, Abergel A, Spektor S, Khafif A, Fliss DM: Patient, caregiver, and surgeon perceptions of quality of life following anterior skull base surgery. Arch Otolaryngol Head Neck Surg 130:1276-1281, 2004

17. Gil Z, Abergel A, Spektor S, Shabtai E, Khafif A, Fliss DM: Development of a cancer-specific anterior skull base qualityof-life questionnaire. J Neurosurg 100:813-819, 2004

18. Gil Z, Fliss DM: Quality of life in patients with skull base tumors: current status and future challenges. Skull Base 20:11-18, 2010

19. Hankinson TC, Palmeri NO, Williams SA, Torok MR, Serrano CA, Foreman NK, et al: Patterns of care for craniopharyngioma: survey of members of the American Association of Neurological Surgeons. Pediatr Neurosurg 49:131-136, 2013

20. Hoffman HJ, De Silva M, Humphreys RP, Drake JM, Smith ML, Blaser SI: Aggressive surgical management of craniopharyngiomas in children. J Neurosurg 76:47-52, 1992

21. Jane JA Jr, Kiehna E, Payne SC, Early SV, Laws ER Jr: Early outcomes of endoscopic transsphenoidal surgery for adult craniopharyngiomas. Neurosurg Focus 28(4):E9, 2010

22. Kassam AB, Gardner PA, Snyderman CH, Carrau RL, Mintz AH, Prevedello DM: Expanded endonasal approach, a fully endoscopic transnasal approach for the resection of midline suprasellar craniopharyngiomas: a new classification based on the infundibulum. J Neurosurg 108:715-728, 2008

23. Kendall-Taylor P, Jönsson PJ, Abs R, Erfurth EM, KoltowskaHäggström M, Price DA, et al: The clinical, metabolic and endocrine features and the quality of life in adults with child- 
hood-onset craniopharyngioma compared with adult-onset craniopharyngioma. Eur J Endocrinol 152:557-567, 2005

24. Komotar RJ, Starke RM, Raper DM, Anand VK, Schwartz TH: Endoscopic endonasal compared with microscopic transsphenoidal and open transcranial resection of craniopharyngiomas. World Neurosurg 77:329-341, 2012

25. Laufer I, Anand VK, Schwartz TH: Endoscopic, endonasal extended transsphenoidal, transplanum transtuberculum approach for resection of suprasellar lesions. J Neurosurg 106:400-406, 2007

26. Leng LZ, Brown S, Anand VK, Schwartz TH: "Gasket-seal" watertight closure in minimal-access endoscopic cranial base surgery. Neurosurgery 62 (5 Suppl 2):ONSE342-ONSE343, 2008

27. Leng LZ, Greenfield JP, Souweidane MM, Anand VK, Schwartz TH: Endoscopic, endonasal resection of craniopharyngiomas: analysis of outcome including extent of resection, cerebrospinal fluid leak, return to preoperative productivity, and body mass index. Neurosurgery 70:110-124, 2012

28. McCoul ED, Anand VK, Bedrosian JC, Schwartz TH: Endoscopic skull base surgery and its impact on sinonasal-related quality of life. Int Forum Allergy Rhinol 2:174-181, 2012

29. McCoul ED, Anand VK, Schwartz TH: Improvements in site-specific quality of life 6 months after endoscopic anterior skull base surgery: a prospective study. J Neurosurg 117:498-506, 2012

30. McCoul ED, Anand VK, Singh A, Nyquist GG, Schaberg MR, Schwartz TH: Long-term effectiveness of a reconstructive protocol using the nasoseptal flap after endoscopic skull base surgery. World Neurosurg 81:136-143, 2014

31. Minamida Y, Mikami T, Hashi K, Houkin K: Surgical management of the recurrence and regrowth of craniopharyngiomas. J Neurosurg 103:224-232, 2005

32. Mortini P, Losa M, Pozzobon G, Barzaghi R, Riva M, Acerno $S$, et al: Neurosurgical treatment of craniopharyngioma in adults and children: early and long-term results in a large case series. J Neurosurg 114:1350-1359, 2011

33. Müller HL, Faldum A, Etavard-Gorris N, Gebhardt U, Oeverink R, Kolb R, et al: Functional capacity, obesity and hypothalamic involvement: cross-sectional study on 212 patients with childhood craniopharyngioma. Klin Padiatr 215:310-314, 2003

34. Pant H, Bhatki AM, Snyderman CH, Vescan AD, Carrau RL, Gardner P, et al: Quality of life following endonasal skull base surgery. Skull Base 20:35-40, 2010

35. Patel KS, Komotar RJ, Szentirmai O, Moussazadeh N, Raper DM, Starke RM, et al: Case-specific protocol to reduce cerebrospinal fluid leakage after endonasal endoscopic surgery. J Neurosurg 119:661-668, 2013

36. Piccirillo JF, Merritt MG Jr, Richards ML: Psychometric and clinimetric validity of the 20-Item Sino-Nasal Outcome Test (SNOT-20). Otolaryngol Head Neck Surg 126:41-47, 2002

37. Pierre-Kahn A, Recassens C, Pinto G, Thalassinos C, Chokron S, Soubervielle JC, et al: Social and psycho-intellectual outcome following radical removal of craniopharyngiomas in childhood. A prospective series. Childs Nerv Syst 21:817824,2005
38. Placantonakis DG, Tabaee A, Anand VK, Hiltzik D, Schwartz TH: Safety of low-dose intrathecal fluorescein in endoscopic cranial base surgery. Neurosurgery 61 (3 Suppl):161-166, 2007

39. Sainte-Rose C, Puget S, Wray A, Zerah M, Grill J, Brauner $\mathrm{R}$, et al: Craniopharyngioma: the pendulum of surgical management. Childs Nerv Syst 21:691-695, 2005

40. Schwartz TH, Fraser JF, Brown S, Tabaee A, Kacker A, Anand VK: Endoscopic cranial base surgery: classification of operative approaches. Neurosurgery 62:991-1005, 2008

41. Shirane R, Ching-Chan S, Kusaka Y, Jokura H, Yoshimoto $\mathrm{T}$ : Surgical outcomes in 31 patients with craniopharyngiomas extending outside the suprasellar cistern: an evaluation of the frontobasal interhemispheric approach. J Neurosurg 96:704-712, 2002

42. Suberman TA, Zanation AM, Ewend MG, Senior BA, Ebert CS Jr: Sinonasal quality-of-life before and after endoscopic, endonasal, minimally invasive pituitary surgery. Int Forum Allergy Rhinol 1:161-166, 2011

43. Tabaee A, Placantonakis DG, Schwartz TH, Anand VK: Intrathecal fluorescein in endoscopic skull base surgery. Otolaryngol Head Neck Surg 137:316-320, 2007

44. Wen BC, Hussey DH, Staples J, Hitchon PW, Jani SK, Vigliotti AP, et al: A comparison of the roles of surgery and radiation therapy in the management of craniopharyngiomas. Int J Radiat Oncol Biol Phys 16:17-24, 1989

45. Yaşargil MG, Curcic M, Kis M, Siegenthaler G, Teddy PJ, Roth P: Total removal of craniopharyngiomas. Approaches and long-term results in 144 patients. J Neurosurg 73:3-11, 1990

46. Zada G, Kintz N, Pulido M, Amezcua L: Prevalence of neurobehavioral, social, and emotional dysfunction in patients treated for childhood craniopharyngioma: a systematic literature review. PLoS ONE 8:e76562, 2013

\section{Author Contributions}

Conception and design: Schwartz, Patel, Raza, Patrona. Acquisition of data: Schwartz, Patel, McCoul, Anand. Analysis and interpretation of data: Schwartz, Patel, Raza, McCoul. Drafting the article: Schwartz, Patel. Critically revising the article: Schwartz, Patel, Raza, Patrona. Reviewed submitted version of manuscript: Schwartz, Patel. Approved the final version of the manuscript on behalf of all authors: Schwartz. Statistical analysis: Schwartz, Patel, McCoul. Administrative/technical/material support: Schwartz, Raza, McCoul, Greenfield, Souweidane, Anand. Study supervision: Schwartz, Raza, McCoul, Patrona, Greenfield, Souweidane.

\section{Correspondence}

Theodore H. Schwartz, Department of Neurological Surgery, Weill Cornell Medical College, NewYork-Presbyterian Hospital, 525 E. 68th St., Box \#99, New York, NY 10065. email: schwarh@med.cornell.edu. 